\begin{tabular}{|l|l|l||}
\hline \multicolumn{2}{|c|}{ PublisherInfo } \\
\hline \hline PublisherName & $:$ & BioMed Central \\
\hline \hline PublisherLocation & $:$ & London \\
\hline \hline PublisherImprintName & $:$ & BioMed Central \\
\hline \hline
\end{tabular}

\title{
Diagnosis of ventilator associated pneumonia, to invade or not?
}

\begin{tabular}{|l|l|l||}
\hline \multicolumn{2}{|c|}{ ArticleInfo } \\
\hline \hline ArticleID & $:$ & 4197 \\
\hline \hline ArticleDOI & $:$ & $10.1186 /$ ccf-2000-5199 \\
\hline \hline ArticleCitationID & $:$ & 5199 \\
\hline \hline ArticleSequenceNumber & $:$ & 56 \\
\hline \hline ArticleCategory & $:$ & Paper Report \\
\hline \hline ArticleFirstPage & $:$ & 1 \\
\hline \hline ArticleLastPage & $:$ & 4 \\
\hline \hline & & RegistrationDate : 2000-5-30 \\
\hline ArticleHistory & $:$ & OnlineDate \\
\hline \hline ArticleCopyright & $:$ & Current Science Ltd2000-5-30 \\
\hline \hline ArticleGrants & $:$ & \\
\hline \hline ArticleContext & $:$ & 1305422 \\
\hline \hline
\end{tabular}




\section{Keywords}

BAL, bronchoalveolar lavage, diagnosis, protected specimen brush sample, PSBS, ventilator-associated pneumonia

\section{Comments}

Ventilator-associated pneumonia (VAP) prolongs intensive care unit (ICU) length of stay and increases the risk of death in critically ill patients. A presumptive diagnosis is often made when a patient on a ventilator develops new radiographically detected infiltrates with signs of new sepsis. One can adopt a noninvasive strategy of treatment based on endotracheal aspirates; however, this may lead to overestimation of VAP. This study compares a non invasive strategy with an invasive approach using scrupulous bronchoscopy based collection of specimens using bronchoalveolar lavage (BAL) or protected specimen brush sample (PSBS) and quantitative cultures. In both groups, antibiotics were held either until a Gram stain was positive or if they had signs of severe sepsis. The antibiotic choice was the same (ATS guideline - additional comment below); the only difference was the sampling technique prior to antibiotic use, ie endotracheal sample or bronchoscopic sample.

Based on their finding of reduced mortality at 14 days, less antibiotic use and earlier attenuation of organ dysfunction, the authors recommend this approach. However, we need to contrast this against the availability of resources, practicality and costs of adopting such an approach in all patients. Also of interest was the disappearance of this mortality benefit at 28 days. The false negative sampling errors or limitations of a PSBS in the diagnosis of VAP also needs to be borne in mind.

\section{Introduction}

Optimal management of patients who are suspected of having VAP is controversial and open to debate. This trial addressed this problem by evaluating both outcomes and antibiotic use in two groups who received antibiotics based on direct examination of organisms recovered either by bronchoscopic means, or by simple endotracheal aspiration. 


\section{Methods}

. Multicentre (31 ICUs), prospective, randomized, unblinded and controlled trial

. Age $>18$ years, mechanical ventilation $>48 \mathrm{~h}$

. Involving 413 patients suspected of having VAP

. VAP defined as a persistent and new radiographic infiltrate associated with at least one of the following:

Purulent tracheal secretions

Fever $>38.3^{\circ} \mathrm{C}$

Leukocytosis

. Excluded if commenced on an antibiotic therapy in 3 days prior to enrollment

. The initial use of empiric antibiotics was guided by Gram stain and the American Thoracic Society guidelines on hospital acquired pneumonia. The antibiotics were continued for 14 days (see below)

. Patients were randomized to either clinical management group (specimen collected using a mucus collector without instilling saline) or in the invasive group (samples taken via bronchoscopy with either bronchoalveolar lavage, PSBS, or both).

. Gram stains were positive in $180 / 209$ in the clinical group, as opposed to $87 / 204$ in the invasive strategy group

. If the Gram stain was negative no antibiotics were used. Antibiotics were also modified on the basis of quantitative cultures (PSBS yielding > 103 colony forming units (CFUs)/mL, BAL yielding $>104 \mathrm{CFU} /$ $\mathrm{mL}$ ) or qualitative cultures (endotracheal samples).

\section{Results}

The 14-day mortality was statistically different in the two groups: $16.2 \%$ in the invasive group compared to $25.8 \%$ in the clinical management group (-9.6 percentage points, $95 \% \mathrm{CI},-17.4$ to -1.8 percentage points, $P=0.022$ ). The mean SOFA (sequential organ failure assessment) scores were significantly lowered at 7 and 14 days but not at 28 days in the invasive group. This group also received significantly fewer antibiotics and had more antibiotic-free days. In addition, infection or colonization by Candida species was more common in the clinical management group $(22.6 \%$ vs $11.3 \%, P=0.0025)$. 


\section{References}

1. Fagon J-Y, Chastre J, Wolff M, Geravis C, Parer-Aubas S, Stephan F, Similowski T, Mercat A, Diehl J-L, Sollet J-P, Tenaillon A, Tenaillon A, VAP trial group: Invasive and noninvasive strategies for management of suspected ventilator-associated pneumonia, a randomized controlled trial. Ann Intern Med. 2000, 132: 621-630.

This PDF file was created after publication. 